\title{
Gross anatomical features of the tongue, lingual skeleton and laryngeal mound of Rhea americana (Palaeognathae, Aves): morpho-functional considerations
}

\author{
Martina Crole · John Soley \\ Received: 11 March 2011 / Revised: 7 March 2012 / Accepted: 9 March 2012 / Published online: 30 March 2012 \\ The final publication is available at http://www.springerlink.com/content/6.j37487920884049/
}

\begin{abstract}
The tongue body of Rhea americana is triangular and partially pigmented with each caudo-lateral margin displaying a round, sub-divided lingual papilla. The tongue root is a smooth, non-pigmented tract of mucosa. The tongue body is supported by the paraglossum and distal half of the rostral projection of the basihyal (RPB), and the tongue root by the proximal half of the RPB, body of the basihyal and proximal ceratobranchials. An urohyal is absent; however, peculiar to $R$. americana, the caudal margin of the cricoid body displays a median projection, which may represent the remnant of the urohyal incorporated into the cricoid. The laryngeal mound is less elevated, the arytenoid cartilages are smaller than in other ratites, and the caudal margin displays pharyngeal papillae that vary in shape and number. The unique morphology of the lingual skeleton and its positioning within the tongue of $R$. americana, the rostral insertion of the $M$. ceratoglossus, the absence of the urohyal (enhanced ventroflexion) and the caudal positioning and mobile attachment of the ensheathed basihyal to the paraglossum would appear to allow independent movement of the tongue body relative to the hyobranchial apparatus. Additionally, the deeply indented base and rostral oval opening in the paraglossum limits the length of cartilage present in the midline of the tongue body. This may allow the tongue the necessary flexibility for the lingual papillae to clean the choana. The cleaning action of the tongue would occur simultaneously
\end{abstract}

Communicated by T. Bartolomaeus.

\footnotetext{
M. Crole $(\bowtie) \cdot$ J. Soley

Department of Anatomy and Physiology,

Faculty of Veterinary Science, University of Pretoria,

Private Bag X04, Onderstepoort 0110, South Africa

e-mail: martina.crole@up.ac.za

with the previously described role of this organ and associated structures during feeding. Thus, the so-called
}

reduced, ancestral tongue of $R$. americana may be structurally and functionally more complex than previously believed.

Keywords Rhea americana • Tongue • Paraglossum . Laryngeal mound $\cdot$ Morphology $\cdot$ Function

\section{Introduction}

There have been numerous reports during the past 180 years on the anatomy of the ratite oropharynx and the structures housed therein (see Crole and Soley 2009a). A renewed interest has recently been shown in the morphology of the upper digestive tract of commercially important ratite species, particularly Struthio camelus (Linnaeus, 1758) (Tivane et al. 2006; Porchescu 2007; Jackowiak and Ludwig 2008; Tadjalli et al. 2008, Tivane 2008; Guimarães et al. 2009) and Dromaius novaehollandiae (Latham, 1790) (Crole and Soley 2009a, b, 2010a, b, 2011), as well as in the feeding mechanism employed by this group of birds (Bonga Tomlinson 2000; Gussekloo and Bout 2005).

The morphology of the ratite tongue has enjoyed particular attention, and a substantial number of papers have addressed this topic (see Crole and Soley 2009a). These studies vary from gross morphological descriptions of the tongue of Rhea pennata (Orbigny, 1834) (Cho et al. 1984), Casuarius casuarius (Linnaeus, 1758) (Gadow 1879; Pycraft 1900), S. camelus and D. novaehollandiae (Faraggiana 1933; Cho et al. 1984; Bonga Tomlinson 2000) to macroscopic and microscopic studies of the tongue of S. camelus (Porchescu 2007; Jackowiak and Ludwig 2008; Tivane 2008; Guimarães et al. 2009) and detailed studies (including light and scanning electron microscopy) of the tongue of $D$. novaehollandiae (Crole and Soley 2009a, b, 2010b). In contrast, only minimal information on the morphology and function of the 
tongue (Owen 1835; Faraggiana 1933; Feder 1972; Bonga Tomlinson 2000; Gussekloo and Bout 2005; Santos et al. 2011) and laryngeal mound (Owen 1835; Faraggiana 1933; Bonga Tomlinson 2000; Gussekloo and Bout 2005) of Rhea americana (Linnaeus, 1758) has been published. The most extensive study of the lingual skeleton is that of Bonga Tomlinson (2000) although its presence was also mentioned by Feder (1972).

Although the tongue of $R$. americana meets the criteria for classification as a rudimentary structure (Gadow 1879; Pycraft 1900; McLelland 1979; Bonga Tomlinson 2000), critical reappraisal of its morphology may suggest a more varied functional role for this organ as previously demonstrated in D. novaehollandiae (Crole and Soley 2009a, b, 2010b). The feeding method of $R$. americana has been documented, and the role of the tongue and hyobranchial apparatus during feeding has been described (Bonga Tomlinson 2000; Gussekloo and Bout 2005). However, the morphological peculiarities of the tongue and lingual skeleton of $R$. americana may reflect additional functions and therefore a more advanced specialisation of these structures, as opposed to representing a basic ancestral form (Bonga Tomlinson 2000) due to their apparent simplicity in comparison with other ratite species.

\section{Materials and methods}

The heads of eleven $R$. americana chicks that had died in shell (1-2 days prior to hatching) $(n=4)$, at hatching $(0$ days post-hatch) $(n=5)$ or at 30 days post-hatch $(n=1)$, and one sub-adult ( 8 months old) bird that had died following predation were used in this study. The sex of the birds was not determined. The birds had been frozen on the farm to preserve the material, and on receipt, the heads were removed and allowed to defrost and subsequently immersed in $10 \%$ neutral-buffered formalin and fixed for a minimum period of $48 \mathrm{~h}$. No obvious deformation of the relevant structures was observed as a result of the fixation technique. The heads were opened (Fig. 1), the lingual and pharyngeal papillae counted, and the relevant anatomical features described and digitally recorded. The tongues and laryngeal mounds were removed from each of the heads by lifting the tongue from the floor of the oropharynx and cutting through the frenulum as well as around the paired ceratobranchials of the hyobranchial apparatus and excising the mucosa ventral to the laryngeal mound and the oesophagus caudal to it. Tongues with attached laryngeal mounds from four chicks and the one sub-adult were stained for cartilage (alcian blue) and bone (alizarin red), and the tissue cleared (Kelly and Bryden 1983) to facilitate a

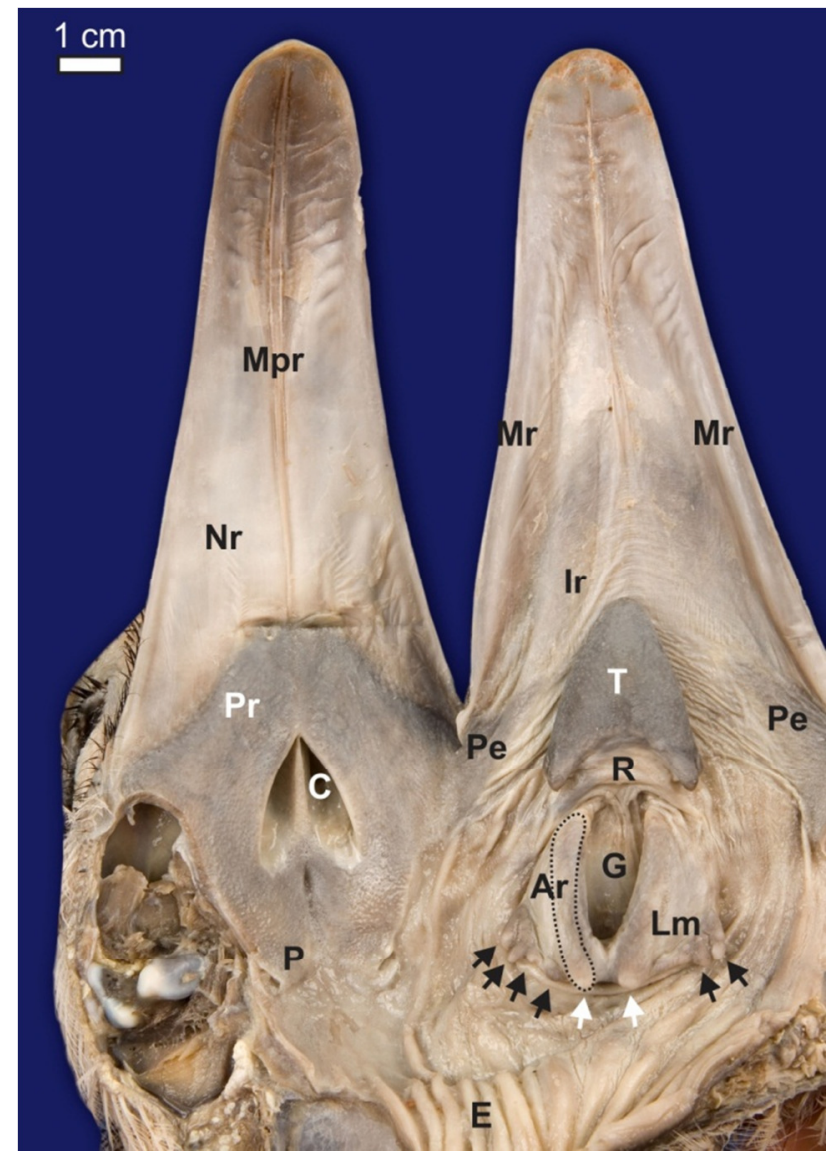

Fig. 1 Sub-adult $R$. americana head opened along the right commissure to reveal the positioning of the tongue and laryngeal mound $(L m)$ within the oropharynx. The body of the tongue $(T)$ lies within the pigmented region $(P r)$ of the roof and the interramal region $(I r)$ of the floor of the oropharynx. The flat tongue root $(R)$ extends from the base of the tongue body to the glottis $(G)$. Other notable features of the oropharynx include the broad non-pigmented mandibular rhamphotheca $(\mathrm{Mr})$, lightly pigmented extensions of the interramal region $(\mathrm{Pe})$ flanking the tongue, pharyngeal papillae (black arrows), medial pharyngeal papillae (white arrows) supported by the arytenoid cartilage (outlined, $A r$ ), median palatine ridge $(M p r)$, non-pigmented region of the roof $(N r)$, choana $(C)$, proximal oesophagus $(E)$ and pharyngeal folds $(P)$ which are attached to the roof

description of the lingual skeleton and laryngeal cartilages. As the specimens were fixed in formalin for more than $2 \mathrm{~h}$, they were first rinsed in running tap water for $24 \mathrm{~h}$ prior to staining (Kelly and Bryden 1983). One tongue was cut into 2- to 3-mm transverse sections from the apex to the base and tongue root (Fig. 4), and another tongue and laryngeal mound were cut longitudinally in the midline (Fig. 5) in order to complete the 3dimensional description of the lingual skeleton.

The terminology used is that of Nomina Anatomica Avium (Baumel et al. 1993). 


\section{Results}

The topographical and morphological features of all specimens examined were similar, irrespective of age, unless otherwise noted in the text.

\section{Tongue}

\section{Tongue body (Corpus linguae)}

The tongue of $R$. americana consisted of a rostral, variably pigmented triangular body and a caudal nonpigmented root (Figs. 1, 2, 3). The tongue body was dorso-ventrally flattened (Fig. 5). The apex (Apex linguae) varied in shape from pointed (Figs. 1, 2a) to gently rounded (Figs. 2b, 4i). With the exception of the caudal margin, the entire dorsal surface (Dorsum linguae) of the tongue body was pigmented $(\mathrm{n}=11)$ (Figs. 2, 3). In one specimen (sub-adult), the entire tongue body (dorsal (Fig. 1) and ventral) was pigmented except for the small ventro-lateral part of the lingual papillae (see below). The base of the tongue was deeply concave (Figs. $1,2 \mathrm{a}, 3 \mathrm{a})$. The junction between the pigmented and nonpigmented regions of the tongue body was abrupt and followed the contour of the tongue base (Fig. 2a). The ventral surface (Ventrum linguae) was similar in colour and appearance to that of the dorsal surface. The transition between the pigmented and non-pigmented regions, as on the dorsal surface, was abrupt. On closer
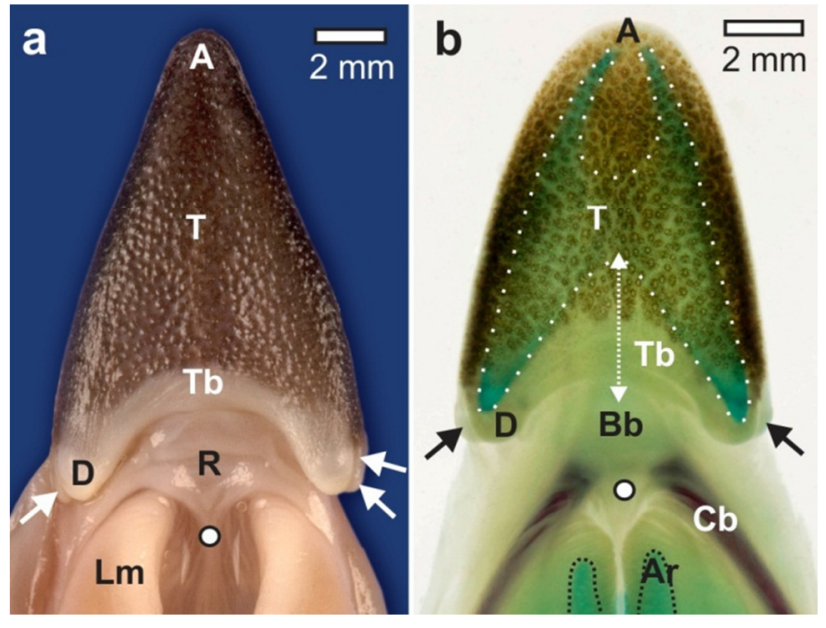

Fig. 2 Dorsal views of $R$. americana chick tongue. a Normal anatomy of the tongue showing the body $(T)$, apex $(A)$, nonpigmented base $(T b)$, tongue root $(R)$ with an extension (white circle) into the laryngeal entrance, as well as the ventro-lateral part (white arrows) and dorso-medial part $(D)$ of the lingual papillae. Rostral portion of the laryngeal mound supported by the arytenoid cartilages $(L m)$. b Specimen stained for cartilage (alcian blue) and bone (alizarin red). Note the paraglossum (dotted outline for clarity) in the tongue body, rostral projection of the basihyal (double-headed dotted white arrow), body of the basihyal $(B b)$, ceratobranchial $(\mathrm{Cb})$ and arytenoid cartilage (black outline, $\mathrm{Ar}$ )

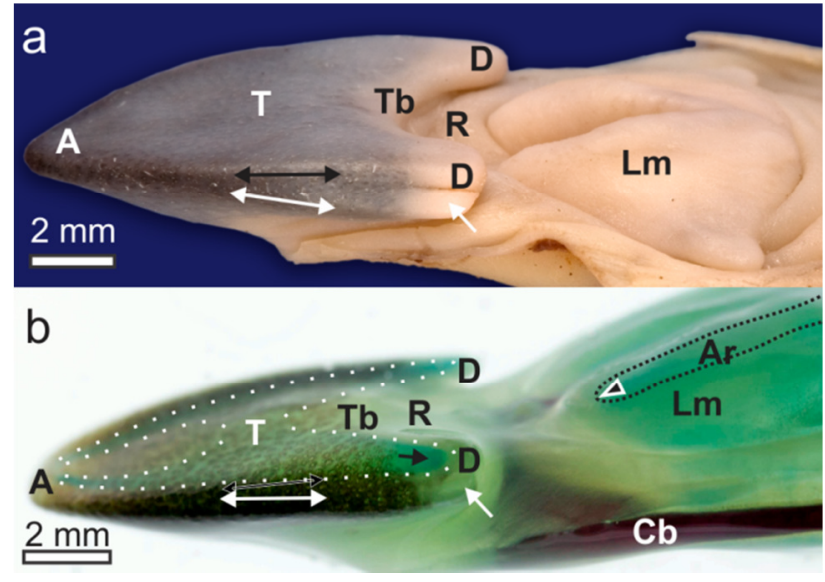

Fig. 3 Dorso-lateral views of the $R$. americana chick tongue body $(T)$, root $(R)$ and laryngeal mound $(\mathrm{Lm})$. a Note the divergence of the lateral tongue margin formed by a shallow groove, with a dorsomedial margin (black double-headed arrow) leading to the dorsomedial part of the lingual papilla $(D)$ and a ventro-lateral margin (white double-headed arrow) leading to the ventro-lateral part of the lingual papilla (white arrow). Note also the origin of the papillae at the level of the most rostral extent of the curved tongue base $(T b)$. Apex $(A)$. b Specimen stained for cartilage (alcian blue) and bone (alizarin red). Note the dorso-medial part of the lingual papilla supported (black arrow) by the paraglossum (white dotted outline for clarity) and the slope of the arytenoid cartilage (black dotted outline for clarity, Ar). The rostral extremity (black triangle) of the arytenoid cartilage lies at the level of the tongue root. Ceratobranchial $(\mathrm{Cb})$

inspection, both the dorsal and ventral pigmented surfaces of the tongue body displayed a pitted or nodular (Figs. 2, 3b, 4i) pattern. The tongue body ventral to the paraglossum contained a large amount of muscular tissue as presented in transverse (Fig. $4 \mathrm{a}-\mathrm{h}$ ) and longitudinal (Fig. 5) sections of the organ.

\section{Margins (Margo linguae)}

The lateral and caudal margins of the tongue body were unembellished and where they converged caudo-laterally, displayed bilateral, rounded lingual papillae or projections (Figs. 1, 2, 3, 4g, h, 5). The papillae were non-pigmented in the chick tongues $(\mathrm{n}=11)$ (Figs. 2a, $3 a, 5)$ although in the sub-adult tongue, the dorso-medial part (see below) of each papilla was pigmented (Fig. 1). The lateral tongue margin was divided longitudinally, from approximately midway along its length, by a shallow groove into dorso-medial and ventro-lateral parts (Fig. 3). From rostral to caudal, the ventral part extended progressively more lateral to the dorsal part. The lingual papilla present on each caudo-lateral margin of the tongue body was also incompletely divided longitudinally by the caudal continuation of the groove. Thus, each papilla was composed of a larger dorso-medial part attached to a smaller ventro-lateral part (Figs. 2, 3, 4g, h). 


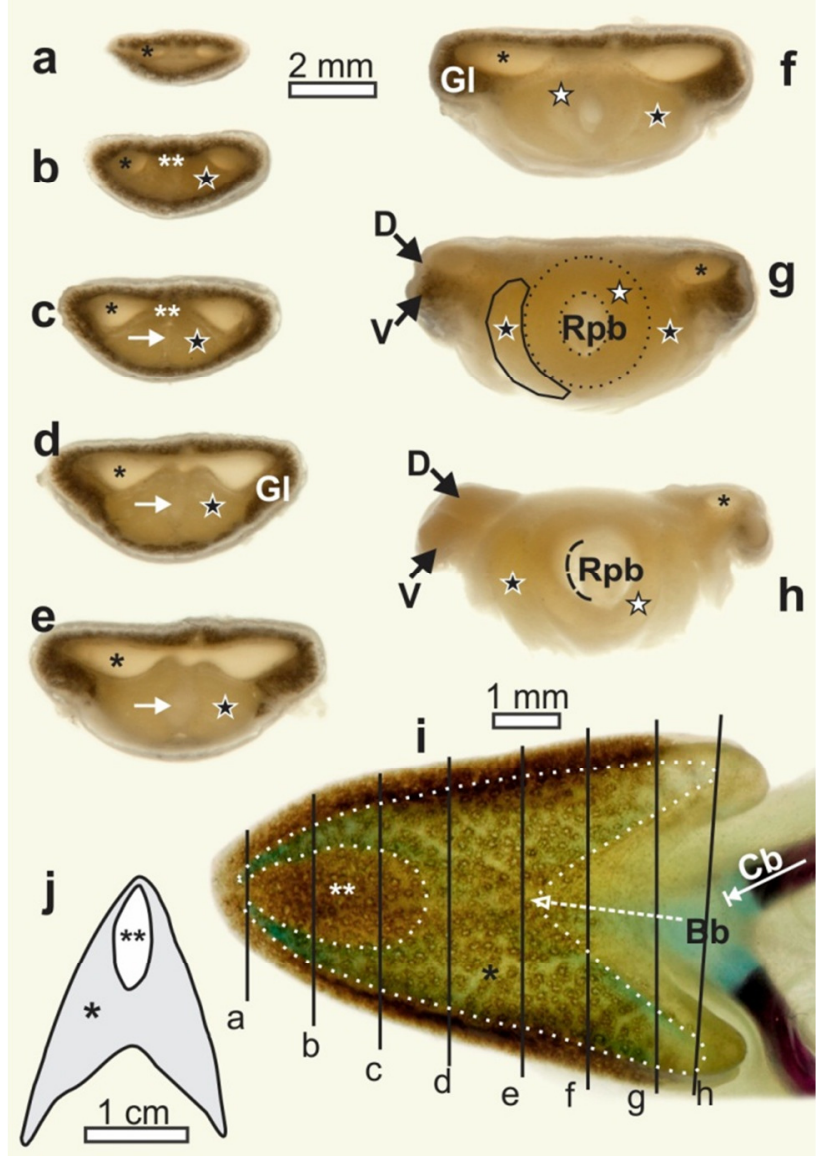

Fig. 4 a-h Transverse sections of a $R$. americana chick tongue showing the topography of the paraglossum (black single asterisk) and the rostral projection of the basihyal (RPB) $(R p b)$ in the tongue body and root. The pigmented surface layer contains mucous glands $(G l)$ that are clearly visible in $\mathbf{i}$ as small dark spots. Muscular tissue is prominent and consists of the M. hyoglossus [white star (outlined in $\mathbf{g}$ )] and the M. ceratoglossus [black star (outlined in $\mathbf{g}$ )]. The $\mathrm{RPB}$ is contained within a sheath which is freely moveable within the M. hyoglossus (curved dotted line in $\mathbf{h}$ ) and which continues rostrally (white arrow in $\mathbf{c - e}$ ). Note the paraglossum in $\mathbf{d}$, $\mathbf{e}$ that is shaped like a propeller. Opening in the paraglossum (white double asterisks), dorso-medial $(D)$ and ventro-lateral $(V)$ parts of the lingual papillae. i Dorsal view of a $R$. americana chick tongue stained for cartilage (alcian blue) and bone (alizarin red) showing the positioning of the paraglossum (black single asterisk, outlined in white), RPB (dotted white arrow), body of the basihyal $(\mathrm{Bb})$ and proximal ceratobranchials $(C b)$ within the tongue body and root. Lines $\mathbf{a}-\mathbf{h}$ represent the approximate transverse sections of the tongue in $\mathbf{a}-\mathbf{h}$. Oval opening in the paraglossum (white double asterisks). $\mathbf{j}$ Sketch of a dorsal view of the paraglossum (black single asterisk) of an 8-month-old $R$. americana. Note how the rostral tips are fused resulting in an oval opening (black double asterisks) in the rostral part of the paraglossum

\section{Tongue root (Radix linguae)}

The tongue root (Figs. 1, 2, 3, 5) was a smooth, nonpigmented tract of mucosa that was situated between the caudal tongue body and the glottis. It occupied the entire

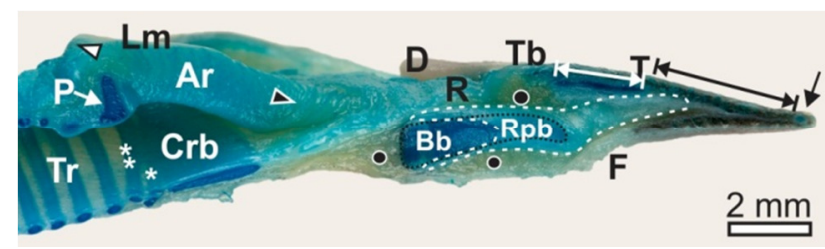

Fig. 5 Median (just off centre) longitudinal section of a $R$. americana chick tongue $(T)$ and laryngeal mound $(\mathrm{Lm})$ stained with alcian blue to emphasise the cartilaginous structures. The elastic basihyal sheath (white dotted outline, for clarity) surrounds the body $(B b)$ and rostral projection $(R p b)$ of the basihyal (black dotted outline, for clarity) and attaches ventral to the oval opening (black double-headed arrow) in the paraglossum (white double-headed arrow and black arrow). Note the rostral (black triangle) to caudal (white triangle) slope of the mucosal-covered arytenoid cartilage (Ar) as well as the first (white single asterisk) and second (white double asterisks) tracheal rings fused with the body of the cricoid cartilage $(C r b)$. Attachment of the frenulum $(F)$, tongue base $(T b)$, tongue root $(R)$, lingual musculature (black circles), dorso-medial part of the lingual papilla $(D)$, procricoid cartilage $(P)$ and trachea $(\operatorname{Tr})$

region between the lingual papillae and the laryngeal entrance. The mucosa of the tongue root was continuous with the mucosa covering the oropharyngeal floor and displayed no definite lateral boundaries. It extended beyond the rostro-lateral edge of the laryngeal mound and tapered gently, dissipating about midway along its lateral edge (Fig. 6). The caudal edge of the tongue root abutted the rostral point of the laryngeal mound and moulded to its contours. A narrow tract of tissue extended from the centre of the tongue root into the laryngeal entrance on the floor of the larynx (Figs. 2, 6b).

\section{Lingual skeleton}

The lingual skeleton of the tongue body consisted of the paraglossum and distal half of the rostral projection of the basihyal (RPB), and in the tongue root, the proximal half of the RPB, body of the basihyal and the proximal part of the ceratobranchials where they joined the body of the basihyal (Figs. 2b, 4i, 5). The urohyal was absent. In the chicks, the paraglossum, viewed dorsally, was shaped like an arrowhead with a rostral, open-ended oval split and a deeply indented V-shaped base (Figs. 2b, 3b, 4i), whereas in the sub-adult bird, the rostral tips were fused leaving an oval opening in the cartilage (Fig. 4j). This resulted in only a short length of cartilage being present in the midline of the tongue body (Figs. $2 b, 3 b, 4 i, j, 5$ ). Each caudo-lateral edge was pointed and supported the dorso-medial lingual papilla (Figs. 2b, 3b, 4i). Viewed in transverse section, it was evident that the paraglossum was situated more dorsally in the tongue body, just below the pigmented surface layer and glands (Figs. 4a-h, 5). The paraglossum was thickest at its lateral edges and thinned medially. The thinner medial part was strengthened on the midline by a ventrally rounded 


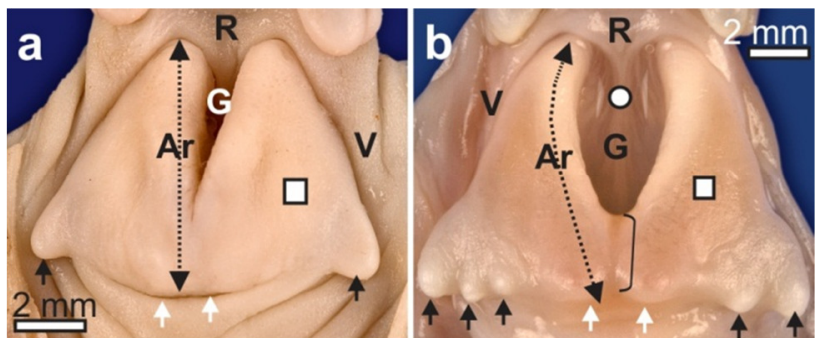

Fig. 6 Dorsal view of two $R$. americana chick laryngeal mounds each formed by two triangular mucosal plates (square). The tongue root $(R)$ tapers around the lateral margins $(V)$ of the laryngeal mound. The glottis $(G)$ is formed by the mucosal-covered arytenoid cartilages ( $A r$, double-headed arrow), and the base of the laryngeal mound is adorned with caudo-lateral pharyngeal papillae (black arrows) and two medial pharyngeal papillae (white arrows) supported by the caudal extremity of the arytenoids. a Note the $\mathrm{V}$ shaped glottis. The lateral pharyngeal papillae are not supported by cartilage, and the medial pharyngeal papillae are not prominent. b The glottis is elliptical, and the extension of the tongue root (circle) into the larynx is clearly seen as well as the caudal median fissure (bracket). In this specimen (30 days old), the caudo-lateral pharyngeal papillae are supported by cartilage

thickening giving the paraglossum the appearance of a propeller (Fig. 4d, e). In transverse section, the dorsal aspect of the paraglossum was flat (Fig. 4a-h). The paraglossum was cartilaginous in all the specimens.

The RPB was cone-shaped with a pointed tip. The tip stretched to the centre of the $\mathrm{V}$-shaped base of the paraglossum and projected just rostral to this point (Figs. $2 b, 4 i, 5)$. Seen externally, this corresponded to approximately half the distance between the caudal edge of the lingual papilla and the apex of the tongue body. The entire basihyal was surrounded by a considerable amount of muscular tissue (Figs. 4g, h, 5). The RPB was immediately contained within a thick connective tissue sheath that attached rostrally on the ventral midline in the region of the oval opening in the paraglossum (Fig. 5). This sheath, even in the formalin fixed state, was very mobile and allowed the tongue body to move rostral (sheath compressed) and caudal (sheath stretched) relative to the RPB. The muscle $[M$. hyoglossus (Bonga Tomlinson 2000)] surrounding the sheath was not attached to it and essentially formed a tube/ tunnel (Fig. $4 \mathrm{~g}, \mathrm{~h}$ ) in which the ensheathed RPB could move in a rostro-caudal direction. The $M$. ceratoglossus (Bonga Tomlinson 2000) extended almost the full length of the tongue and inserted rostrally, ventral to the oval opening in the paraglossum (Fig. 4). The basihyal (RPB and body) was cartilaginous in all the chick specimens and in the sub-adult bird showed signs of ossification. The ceratobranchials were ossified in all the specimens.

Laryngeal mound (Mons laryngealis)
The laryngeal mound projected dorsally from the floor of the oropharynx and was situated caudal to the tongue root, rostral to the oesophagus and ventral to the choana (Fig. 1). When viewed dorsally, the laryngeal mound appeared to consist of two adjoining, raised, nonpigmented, triangular mucosal plates (Figs. 1, 6). The rostral aspect of the mound was formed by the paired apices of the triangular plates that were separated by the glottis. The apices varied in shape from pointed (Fig. 1) to rounded (Fig. 6) and abutted the caudal edge of the tongue root. The Rima glottis occupied the rostral half to three quarters of the laryngeal mound and was formed by the medial sides of the triangular plates. The glottis varied in shape from V-shaped (Fig. 6a) to elliptical (Figs. 1, 6b). In some specimens, the caudal termination of the glottis appeared to be continued caudally on the mound as an ill-defined median fissure (Fig. 6b).

The base of the laryngeal mound was formed by the combined caudal sections of the twin mucosal plates. This part of the mound was embellished with varying numbers of small, blunt pharyngeal papillae (Figs. 1, 6). In all specimens, a prominent pharyngeal papilla was present at each caudo-lateral margin of the base (Figs. 1, 6) and, although not that obvious in all specimens (Fig. $6 a)$, the base also displayed twin pharyngeal papillae or prominences on the midline at the junction of the two mucosal plates (Figs. 1, 6b). These centrally positioned papillae, which were more prominent in some specimens than in others (Figs. 1, 6), corresponded to, and were supported by, the caudal extremity of the arytenoid cartilages (see below) (Fig. 7). In the 30-day-old chick, the caudo-lateral pharyngeal papillae were supported by cartilage (Fig. 6b), which in the sub-adult was ossified. In the younger chicks, the caudo-lateral pharyngeal papillae were fleshy structures (Fig. 6a). Of the 12 specimens examined, 8 displayed the pattern described above (Fig. 6a), whilst the remaining specimens exhibited varying numbers and arrangements of the pharyngeal papillae. In addition to the central pair of papillae, one specimen demonstrated twin papillae on each caudo-lateral edge, another displayed three smaller papillae medial to the left and a single papilla medial to the right caudo-lateral papilla (Fig. 1). Two specimens exhibited two papillae and one papilla, respectively, positioned medial to each caudo-lateral papilla (Fig. 6b). The total number of pharyngeal papillae therefore varied between $4(n=8), 6$ $(\mathrm{n}=1), 7(\mathrm{n}=1)$ and $8(\mathrm{n}=2)$.

The laryngeal skeleton was composed of four cartilages [as determined by differential staining (Kelly and Bryden 1983)], namely the cricoid, procricoid and paired arytenoid cartilages (Fig. 7). The cricoid was the largest of the laryngeal cartilages and was circular in shape forming the ventral, lateral and caudo-dorsal borders of the larynx (Figs. 7, 8). The broad ventral body 


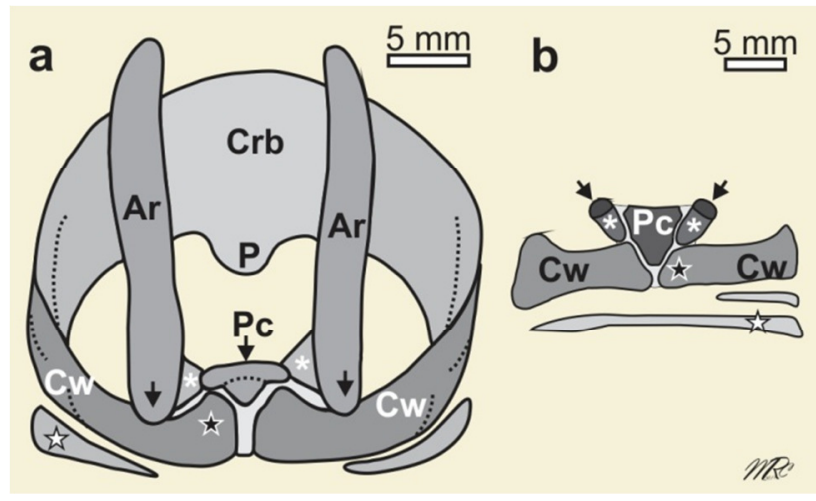

Fig. 7 Schematic representation of the laryngeal cartilages of an 8 -month-old $R$. americana indicating the cricoid, procricoid $(P c)$ and paired arytenoid $(A r)$ cartilages. a Dorso-caudal view. The junction between the medial part of the arytenoids (asterisk) and the procricoid is distorted in this view. Note the median projection $(P)$ of the cricoid body $(\mathrm{Crb})$, bulbous termination (black star) of the cricoid wings $(C w)$, caudal extremity of the arytenoids (black arrows), which support the caudo-medial pharyngeal papillae and tracheal rings (white star). The first two tracheal rings fused with the cricoid have been omitted from this sketch. b Caudal view. Note the relationship between the cricoid wings, procricoid and medial aspect of the arytenoid cartilages. Caudal extremity of the arytenoids (arrows)

(Corpus cricoidea) was characterised by a smooth cranial margin, whereas the mid caudal margin displayed a small caudally directed median projection (Fig. 7a), which was flanked on either side by smaller, curved caudo-medially directed extensions forming the first tracheal ring (Fig. 8). In some specimens, the first tracheal ring fused with the median projection, leaving two small holes representing the enclosed space (bisected by the median projection) between the ring and the cricoid cartilage (Fig. 8b). Other variations noted were overlapping of the first tracheal ring by the median projection (Fig. 8d) and fusion of the projection to the second tracheal ring (Fig. $8 \mathrm{c})$. The broad body of the cricoid extended dorsocaudally as two thinner lateral wings (Ala cricoidea), ending just before the midline (Fig. 7). The slightly bulbous termination (Fig. 7) of each wing was situated ventral to the caudal end of the overlying procricoid and arytenoid cartilages. The terminal part of the cricoid wings remained separated and did not fuse with each other (Fig. 7). The first 2-3 tracheal rings fused with the caudal margin of the body and wings of the cricoid cartilage (Figs. 5, 8). The cricoid was cartilaginous in all the chick specimens, and in the sub-adult, the rostral margins stained faintly with alizarin red indicating possible ossification. The procricoid cartilage was circular (chicks) to roughly triangular (sub-adult) and was situated between the caudal ends of the arytenoid cartilages dorsal to the termination of the wings of the cricoid (Fig. 7). In the chicks, it appeared isolated from the surrounding cartilages; however, in the sub-adult, it joined the caudal ends of the arytenoid cartilages and the

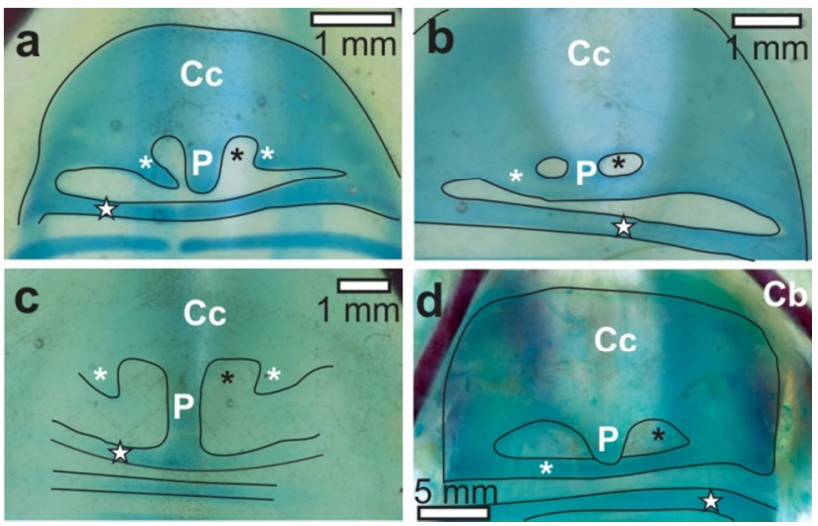

Fig. 8 Ventral view of the cricoid cartilage $(C c)$ of $R$. americana chicks (a-c) and a sub-adult (d) stained for cartilage (alcian blue) and bone (alizarin red). There are varying degrees of fusion between the caudal median projection $(P)$ and the first (white single asterisk) and second (star) tracheal rings. Note the space (black single asterisk) enclosed by the first tracheal ring, and the fusion of the first and second tracheal rings with the cricoid. Structures have been outlined in black for clarity. a The median projection is unattached to the surrounding structures. $\mathbf{b}$ The median projection is fused to the first tracheal ring resulting in two small enclosed spaces. c The median projection is fused with the second tracheal ring. d The median projection slightly overlaps but is attached to the complete first tracheal ring. Ceratobranchial $(\mathrm{Cb})$

rostro-medial margins of the wings of the cricoid (Fig. 7). The procricoid was cartilaginous in all the specimens. The arytenoid cartilages formed long, paired bars and were the most dorsal component of the larynx (Figs. 3b, $5,7)$. They were sloped, with the rostral extremity level with the tongue root and the caudal extremity elevated dorsally (Figs. 3b, 5). They were imbedded in the medial aspect of the two triangular mucosal plates, essentially forming the lips of the glottis (Figs. 1, 2b, 6). The arytenoid cartilages extended rostral to the underlying cricoid body and caudal to the cricoid wings (Fig. 7a). The medial aspect of each arytenoid, just rostral to its caudal extremity, joined with the procricoid cartilage (Fig. 7). The arytenoids were cartilaginous in all the specimens.

\section{Discussion}

The urohyal is absent in $R$. americana (Parker 1866; Bonga Tomlinson 2000; present study), a situation unique amongst palaeognaths (Bonga Tomlinson 2000). Bonga Tomlinson (2000) speculates that the separate globular body ("copula II") caudal to the basihyal in the $R$. americana embryos, reported by Müller (1963), may be homologous to the urohyal. This structure is apparently lost in later development and is absent in juveniles and adults (Bonga Tomlinson 2000). In the light of the above observations, it is possible that the median projection present on the caudal margin of the body of the cricoid 
cartilage in $R$. americana (present study) may be a remnant of the urohyal. There is no reference in the literature (White 1975; McLelland 1989; King 1993) to a median projection on the caudal margin of the cricoid cartilage in other avian species. Therefore, $R$. americana may very well possess the urohyal, although greatly reduced and incorporated into the cricoid cartilage of the larynx.

In $R$. americana (Parker 1866; present study) and Apteryx australis (Shaw, 1813) (Parker 1891), the RPB extends only to the point of the $\mathrm{V}$-shaped base of the paraglossum, whereas in D. novaehollandiae (Crole and Soley 2009a), it runs almost the full length of the paraglossum and in $S$. camelus the full length of the tongue (Tivane 2008). In $R$. americana, the tongue body is supported by the paraglossum and the distal half of the $\mathrm{RPB}$, and the tongue root by the proximal half of the RPB, the body of the basihyal and the proximal ceratobranchials. In marked contrast, the tongue body of D. novaehollandiae is supported by the paraglossum, the entire basihyal (body and rostral projection), the proximal ceratobranchials as well as a small section of the urohyal, and the tongue root by the ceratobranchials and urohyal (Crole and Soley 2009a, b). The tongue body of $S$. camelus is supported by the paraglossalia and the entire $\mathrm{RPB}$, and the tongue root by the body of the basihyal, proximal ceratobranchials, proximal urohyal and the rostral projection of the cricoid cartilage of the larynx (Tivane 2008). Therefore, in comparison, the tongue body of $R$. americana is supported by the least elements of the lingual skeleton and that of $D$. novaehollandiae by the most. Conversely, the tongue root of $D$. novaehollandiae contains the least supporting elements and that of $S$. camelus the most.

The laryngeal mound of $R$. americana was supported by the cricoid, procricoid and two arytenoid cartilages that were also identified in D. novaehollandiae (Crole and Soley 2010a), S. camelus (Tivane 2008) and other birds (McLelland 1989). The existence of a thyroid cartilage reported by Fowler (1991) was not indicated in the present study. The cricoid of $R$. americana is relatively simple and in common with that of $D$. novaehollandiae (Crole and Soley 2010a) and S. camelus (Tivane 2008) has no separate connection between the body and wings as reported in Gallus gallus (Linnaeus, 1758) (White 1975) and for other birds (McLelland 1989). The rostral margin of the cricoid body in $R$. americana was rounded and did not display the rostral projection described in S. camelus (Tivane 2008) or the smaller projection illustrated in D. novaehollandiae (McLelland 1989-Sketch by S.S. White). However, the median projection on the caudal margin of the cricoid in $R$. americana (as discussed above) seems to be unique to this species and has not been reported in other birds, including other ratite species.

\section{Morpho-functional considerations}

In comparison with the laryngeal mound of $D$. novaehollandiae (Crole and Soley 2010a) and S. camelus (Göppert 1903; Faraggiana 1933; Porchescu 2007; Tadjalli et al. 2008; Tivane 2008), that of $R$. americana is less raised off the oropharyngeal floor. The caudal margin of the laryngeal mound in birds is sloped towards the oesophagus, and the pharyngeal folds overlie this sloped area, allowing for closure of the oesophagus during respiration (Nickel et al. 1977). The pharyngeal folds of $R$. americana are much reduced and are firmly attached to the roof of the oropharynx (see Fig. 1), and the flatter laryngeal mound would seem to provide sufficient apposition between the glottis and choana without the assistance of pharyngeal folds to seal off the oesophagus during respiration. Although the laryngeal mound of ratite species is reported to be smooth (McLelland 1989) and is a feature noted in D. novaehollandiae (Crole and Soley 2010a), many bird species display pharyngeal papillae on the laryngeal mound caudal to the glottis (King and McLelland 1984; Bailey et al. 1997; McLelland 1989). The considerable variation in the appearance and number of pharyngeal papillae noted in the present study was a feature not previously reported for $R$. americana (Faraggiana 1933; Bonga Tomlinson 2000; Gussekloo and Bout 2005). This variability in size, number and appearance suggests that the pharyngeal papillae may be rudimentary in nature and are not an integral part of the functioning of the laryngeal mound. However, in those birds with better developed and more numerous pharyngeal papillae, and which in the older birds were supported by cartilage or bone, it is feasible that these structures may assist in freeing adhered food particles immediately adjacent to the pharyngeal folds during swallowing.

The unique shape of the paraglossum in $R$. americana poses interesting questions. There is little doubt that the placement of the lingual skeleton and the associated musculature allows for movement of the tongue body independent of the hyobranchial apparatus. However, the function of the oval opening in the paraglossum, at least in sub-adult birds, is not clear. As a result of the deeply indented base and the rostral oval opening of the paraglossum in chicks, the median part of the tongue body is supported only by a short length of cartilage (see Figs. 2b, 3b, 4i, 5). In addition, this short median part is ventrally rounded and thicker than the cartilage immediately adjacent to it (see Fig. 4d, e). It may be speculated that these structural features would permit a hinged movement of the paraglossum. This would allow 
the lateral tongue margins to move ventrally [by action of the M. hyoglossus (Bonga Tomlinson 2000)] relative to the dorsal midline of the tongue, decreasing the distance between the lingual papillae. As the distance between the lingual papillae is greater than the width of the choana (see Fig. 1), this degree of flexibility may allow them to move closer together enabling them to clean the choana during retraction of the tongue. Furthermore, as each dorso-lateral papilla is supported by the paraglossum, this may offer them the required rigidity for such a function. Although structurally different, a similar function of cleaning the choana has been proposed for the laryngeal mound and tongue root in D. novaehollandiae (Crole and Soley 2010a).

A connective tissue sheath, the basihyal sheath (Bonga Tomlinson 2000), which appears to be a feature unique to $R$. americana, surrounds the RPB. This structure was confirmed in the present study which further revealed that it ensheathed the entire RPB and attached ventral to the oval opening of the paraglossum. The sheath was therefore not as narrow or as short (ending before the rostral tip of the RPB) as illustrated by Bonga Tomlinson (2000). The existence of the basihyal sheath and the arrangement of the surrounding musculature would suggest that the RPB can move independently of the paraglossum.

In A. australis, the urohyal, enclosed in a sheath ventral to the larynx, offers stability for the protractile and retractile movements of the tongue (Parker 1866). Bonga Tomlinson (2000) states that tongue extension rostral to the basihyal [by action of the M. genioglossus (Bonga Tomlinson 2000)] enhances ventroflexion of the tongue body. This movement is limited by the presence of the urohyal, therefore leading to the conclusion that the tongue of $R$. americana is most flexible and the tongue of $S$. camelus the least flexible amongst ratite species (Bonga Tomlinson 2000). The unique morphology of the lingual skeleton and its positioning within the tongue of $R$. americana, as outlined above, would certainly support the above statement. Based on the study of the musculature by Bonga Tomlinson (2000) and observations from the present study, the following morphological features in $R$. americana strongly suggest that the tongue is able to move independently of the hyobranchial apparatus: the presence of the mobile basihyal sheath and the tunnel formed by the $M$. hyoglossus around this sheath (rostro-caudal movement of the basihyal); the rostral insertion of the $M$. ceratoglossus (ventroflexion); the absence of the urohyal (unhindered ventroflexion); the caudal position and mobile attachment of the basihyal to the paraglossum (protraction and ventroflexion); and the heavy musculature in the tongue body and the unique, paired $M$. basiarytaenoideus attaching the basihyal sheath to the rostral point of the arytenoid cartilages. This phenomenon has not been noted for other ratite species.

\section{Conclusion}

Bonga Tomlinson (2000) states that "the neognathous feeding system could have been derived from the basic, putatively ancestral form of the hyolingual apparatus present in the paleognathous rhea or tinamou', thus implying that the arrangement of these elements in $R$. americana represents the most basic pattern amongst palaeognaths. The hyolingual apparatus of $R$. americana may appear less complex in comparison with that in other ratite species; however, its morphology clearly allows for a larger range of movement of the tongue, thus questioning the assumption that this species displays the most basic form of the hyolingual apparatus in palaeognaths. It can additionally be proposed that the hyolingual apparatus of $R$. americana is not only highly specialised and adapted for its role in feeding (Bonga Tomlinson 2000; Gussekloo and Bout 2005) but is also structurally designed for the simultaneous cleaning of the choana during each swallowing cycle. In this species, the apparent simplicity of the design of the hyolingual apparatus has disguised the complexity of its function. It may be prudent, therefore, to identify the unique specialisations of each ratite species rather than to assume that a more basic form represents the ancestral condition.

Acknowledgments The authors thank Mrs Petra Rough and Mrs Pauline Henderson (Emu Ranch, Rustenburg, Northwest Province, South Africa) for providing the $R$. americana heads, Mrs Charmaine Vermeulen for the photography and the National Research Foundation (NRF) and the University of Pretoria, South Africa, for financial support. The authors wish to thank the anonymous reviewers for their valuable comments.

\section{References}

Bailey TA, Mensah-Brown EP, Samour JH, Naldo J, Lawrence P, Garner A (1997) Comparative morphology of the alimentary tract and its glandular derivatives of captive bustards. J Anat 191:387-398

Baumel JJ, King AS, Breazile JE, Evans HE, Vanden Berge JC (1993) Handbook of avian anatomy: Nomina Anatomica Avium, $2^{\text {nd }}$ edn. Nuttall Ornithological Club, Cambridge

Bonga Tomlinson CA (2000) Feeding in paleognathous birds. In: Schwenk K (ed) Feeding: form, function, and evolution in tetrapod vertebrates. Academic Press, San Diego, pp 359-394

Cho P, Brown B, Anderson M (1984) Comparative gross anatomy of ratites. Zoo Biol 3:133-144

Crole MR, Soley JT (2009a) Morphology of the tongue of the emu (Dromaius novaehollandiae). I. Gross anatomical features and topography. Onderstepoort J Vet Res 76:335-345

Crole MR, Soley JT (2009b) Morphology of the tongue of the emu (Dromaius novaehollandiae). II. Histological features. Onderstepoort J Vet Res 76:347-361 
Crole MR, Soley JT (2010a) Gross morphology of the intra-oral rhamphotheca, oropharynx and proximal oesophagus of the emu (Dromaius novaehollandiae). Anat Hist Embr 39:207-218

Crole MR, Soley JT (2010b) Surface morphology of the emu (Dromaius novaehollandiae) tongue. Anat Hist Embr 39:355365

Crole MR, Soley JT (2011) Distribution and structure of glandular tissue in the oropharynx and proximal oesophagus of the emu (Dromaius novaehollandiae). Acta Zool (Stockholm) 92:206215

Faraggiana R (1933) Sulla morfologia della lingua e del rialzo laringeo di alcune specie di Uccelli Ratiti e Carenati non comuni. Boll Musei Zool Anat Comp 43:313-323

Feder F-H (1972) Zur mikroskopischen Anatomie des Verdauungsapparates beim Nandu (Rhea americana). Anat Anz 132:250-265

Fowler ME (1991) Comparative clinical anatomy of ratites. J Zoo Wildlife Med 22:204-227

Gadow H (1879) Versuch einer vergleichenden Anatomie des Verdauungssystemes der Vo"gel. Jena Z Med Naturw 13:92171

Göppert E (1903) Die Bedeutung der Zunge für den sekunda“ren Gaumen und den Ductus nasopharyngeus. Morph Jb 31:311359

Guimarães JP, Mari RB, De Carvalho HS, Watanabe L (2009) Fine structure of the dorsal surface of ostrich's (Struthio camelus) tongue. Zool Sci 26:153-156

Gussekloo SWS, Bout GR (2005) The kinematics of feeding and drinking in palaeognathous birds in relation to cranial morphology. J Exp Biol 208:3395-3407

Jackowiak H, Ludwig M (2008) Light and scanning electron microscopic study of the structure of the ostrich (Strutio camelus) tongue. Zool Sci 25:188-194

Kelly WL, Bryden MM (1983) A modified differential stain for cartilage and bone in whole mount preparations of mammalian fetuses and small vertebrates. Stain Technol 58:131-134

King AS (1993) Apparatus respiratorius [Systema respiratorium]. In: Baumel JJ, King AS, Breazile JE, Evans HE, Vanden Berge JC (eds) Handbook of avian anatomy: Nomina Anatomica Avium, 2nd edn. Nuttall Ornithological Club, Cambridge

King AS, McLelland J (1984) Digestive system. In: Birds-their structure and function, 2nd edn. Baillière Tindall, London, pp 84-109

McLelland J (1979) Digestive system. In: King AS, McLelland J (eds) Form and function in birds, vol 1. Academic Press, London, pp 69-92

McLelland J (1989) Larynx and trachea. In: King AS, McLelland J (eds) Form and function in birds, vol 4. Academic Press, London, pp 69-104

Müller HJ (1963) Die Morphologie und Entwicklung des Craniums von Rhea americana Linne. II Viszeralskelett, Mittelohr, und Osteocranium. Zeit Wissensch Zool 168:35-118

Nickel R, Schummer A, Seiferle E (1977) Digestive system. In: Anatomy of the domestic birds. Verlag Paul Parey, Berlin, pp 40-61

Owen R (1835) Division I. Organs in plants and animals for the special purposes of the individual. Subdivision VIII. Organs of sense. Series II. Organ of taste. In birds. In: Royal College of Surgeons of England. Museum, Owen R (ed) Descriptive and illustrated catalogue of the physiological series of comparative anatomy contained in the museum of the Royal College of Surgeons in London. Vol. 3. Part 1. Nervous system and organs of sense. Richard Taylor, London, pp 72-76
Parker WK (1866) On the structure and development of the skull in the ostrich tribe. Phil Trans Roy Soc Lond 156:113-183

Parker TJ (1891) Observations on the anatomy and development of apteryx. Phil Trans Roy Soc Lond B 182:25-134

Porchescu G (2007) Comparative morphology of the digestive tract of the black African ostrich, hen and turkey. Thesis, Agrarian State University of Moldova

Pycraft WP (1900) On the morphology and phylogeny of the Palaeognathae (Ratitae and Crypturi) and Neognathae (Carinatae). Trans Zool Soc Lond 15:149-290

Santos TC, Fukuda KY, Guimarães JP, Oliveira MF, Miglino MA, Watanabe I-S (2011) Light and scanning electron microscopy study of the tongue in Rhea americana. Zool Sci 28:41-46

Tadjalli M, Mansouri SH, Poostpasand A (2008) Gross anatomy of the oropharyngeal cavity in the ostrich (Struthio camelus). Iran J Vet Res 9:316-323

Tivane C (2008) A morphological study of the oropharynx and oesophagus of the ostrich (Struthio camelus). Dissertation, University of Pretoria

Tivane C, Soley JT, Groenewald HB (2006) Gross morphological features of the oropharyngeal cavity of the ostrich (Struthio camelus). In: Programme of the 36th annual conference of the Anatomical Society of Southern Africa, Golden Gate, Free State, South Africa, p 21

White SS (1975) Larynx. In: Getty R, Rosenbaum CE, Ghoshal NG, Hillmann D (eds) Sisson and Grossman's the anatomy of the domestic animals, vol 2. W.B. Saunders Company, Philadelphia, pp 1891-1897 